\title{
Effect of Hydrochloric Acid on Resin Cement Microleakage in Zirconia-Reinforced Lithium Silicate Crowns
}

\author{
Nassief S1 Ali $\mathrm{OA}^{2}$, Kostagianni $\mathrm{A}^{2}$ and Tsakalelli V2* \\ ${ }^{1}$ Department of Advanced and Graduate Education Department, Tufts University \\ School of Dental Medicine, USA \\ ${ }^{2}$ Department of Prosthodontics, Tufts University School of Dental Medicine, USA
}

*Corresponding author: Vasiliki Tsakalelli, Department of Prosthodontics, Tufts University School of Dental Medicine, One Kneeland Street, Boston, MA 02111, USA, Tel: 6176360319; Fax: +1617 636 6583; Email: Vasiliki.Tsakalelli@tufts.edu

\section{Abstract}

Purpose: To evaluate the microleakage of different resin cements after immersion of zirconia-reinforced lithium silicate crowns (ZLS) in hydrochloric acid (HCl) solution.

Materials and Methods: Forty-five extracted non-carious human molars were prepared for porcelain crowns. The teeth were randomized into three different groups according to the resin cements tested: RelyX ${ }^{\mathrm{TM}}$ UniCem (3M, ESPE), Variolink ${ }^{\circledR}$ Esthetic Dual-cure (Ivoclar Vivadent) and Panavia ${ }^{\text {TM }} 21$ (Kuraray America Inc.). Five replicates were used as a control for each of the resin cements. ZLS crowns were designed and milled from Celtra® Duo blocks using CEREC computer-aided design, computer assisted manufacturing (CAD/CAM) system and then cemented to the prepared teeth using the assigned cement according to the manufacturers' guidelines. The samples were thermal cycled between water temperatures of $5^{\circ} \mathrm{C}$ and $55^{\circ} \mathrm{C}$ for 5,000 cycles with a 15 second dwell-time after each temperature. In order to mimic one year of clinical time in a patient's mouth, the samples of the experiment group were subjected to 91 one-hour cycles in $\mathrm{HCl}(\mathrm{pH} 2)$ followed by one hour in artificial saliva; samples were submersed in artificial saliva for 91 hours. The specimens then were submerged in 50\% silver nitrate solution for 24 hours followed by a developer solution for eight hours. All samples were embedded in clear epoxy resin and sectioned in a buccolingual direction at $0.5 \mathrm{~mm}$. Sections were analyzed by a stereomicroscope at a magnification of 10X. Proportion of microleakage was calculated by dividing the total length of the dye penetration by the total length of the restoration. Data were analyzed with the Kruskal-Wallis test and Mann-Whitney U test with the Bonferroni correction.

Results: All experimental groups demonstrated higher microleakage scores than the control groups for all types of cement. There was no statistically significant difference in median microleakage among the three cements tested ( $p>05)$. 


\section{Open Access Journal of Dental Sciences}

Panavia 21 group showed the highest median microleakage score (59.24\%) followed by Rely-X UniCem (54.95\%) and Variolink Esthetic (45.83\%).

Conclusion: Within the limitations of this in-vitro study, all the resin cements tested exhibited microleakage to some degree, especially when they were exposed to the hydrochloric acid solution.

Keywords: All ceramic restoration; CAD/CAM crowns; Zirconia-reinforced lithium silicate; Marginal integrity; Marginal adaptation; Marginal fit; Thermocycling

Abbreviations: ZLS: Zirconia-Reinforced Lithium Silicate; HCI: Hydrochloric Acid; GERD: Gastroesophageal Reflux.

\section{Introduction}

Ceramic restorations continually increase in popularity due to their superior aesthetics and biocompatibility as well as their reliability and effectiveness as long-term restorative materials [1-4]. Their fabrication methods include either conventional laboratory techniques or CAD/CAM technology systems, which have been introduced to the market during the last decade [5-7]. Among the different types of luting agents available for all ceramic restorations, resin cements are well established as the material of choice, since they demonstrate superior characteristics over other luting agents such as zinc phosphate, polycarboxylate, and glass ionomer cements [8-11].

Resin cements consist of an organic matrix through which phosphoric acid methacrylate reacts with the hydroxyapatite of the tooth structure, leading stronger and more durable bond between the tooth surface and the ceramic [12]. Resin cements demonstrate high bond strength as well as high tensile and compressive strength. Furthermore, they have low solubility and high flexural properties, which are both essential in preventing the debonding process. Therefore, these cements could maintain an acceptable margin reducing the amount of leakage, caries, and restoration failure [13-16].

Marginal microleakage is the penetration of bacteria, liquids, molecules, or ions between the restorative material and the abutment tooth. It is one of the most serious complications associated with all ceramic restorations [17]. It can lead to secondary caries, marginal staining, pulpal hypersensitivity, and ultimately, failure and need for replacement of the restoration [18-20]. Factors contributing to microleakage include the

Tsakalelli V, et al. Effect of Hydrochloric Acid on Resin Cement Microleakage in Zirconia-Reinforced Lithium Silicate Crowns. J Dental Sci 2019, 4(4): 000239. difference between the coefficient of thermal expansion of the dental restorative material and the restored tooth, shrinkage of the luting agent, and inadequate marginal adaptation [21]. Although no restoration can reach the ideal marginal adaptation, all ceramic restorations have been clinically accepted within certain degree of marginal adaptation and as a consequence potential microleakage. Studies indicate that the clinically acceptable amount of marginal gap for ceramic restorations ranges from 20-150 $\mu \mathrm{m}[22,23]$.

Gastroesophageal reflux (GERD) occurs when an individual has no control over the passage of gastric contents. This common medical condition can alter the physiologic $\mathrm{pH}$ value in the oral cavity and adversely affect the tooth structure and dental restorations [24]. In that case, the frequent presence of hydrochloric acid, which has been reported to have a pH below 2.0 and is present in the gastric fluid, will lower the $\mathrm{pH}$ value below the critical pH 5.5 of dental enamel and create a constant acidic environment that can damage the hard and soft tissue [25-27]. Furthermore, GERD patients may present with an impaired salivary flow and reduced buffering capacity, complications that might amplify the effect of acid in the oral cavity [28-31]. As a dental consequence tooth erosion may occur, which is an irreversible loss of tooth structure predominantly found in the palatal and lingual surfaces of maxillary teeth [32-34].

While this patient population is in need for medical treatment, they may also require interdisciplinary dental treatment for the oral manifestations, which commonly involves onlays, veneers or full coverage crowns [35,36]. Although hydrochloric acid has a destructive effect on natural teeth, prolonged exposure to acid may also affect the longevity of ceramic restorations by causing ceramic breakdown or microleakage $[37,38]$.

No evidence has been identified regarding the effect of hydrochloric acid on the microleakage of resin cements under ceramic restorations. Several resin-based dental 
cements are available in the market and some of them are most commonly used as RelyX UniCem, Panavia and Variolink II; however, the extent of microleakage might be unpredictable and dependent on the types of cement used [8]. Therefore, the aim of the present in vitro study was to evaluate the effect of $\mathrm{HCl}$ on microleakage of RelyX UniCem, Panavia 21 and Variolink Esthetic resin cements after immersion of zirconia-reinforced lithium silicate crowns (ZLS) in $\mathrm{HCl}$ solution. The first null hypothesis was that a significant difference in microleakage among the three types of resin cements Panavia 21, RelyX Unicem and Variolink Esthetic would be found when utilized on ZLS crowns after immersion in $\mathrm{HCl}$ solution. The second null hypothsesis was that the exposed ZLS to $\mathrm{HCl}$ solution would exhibit higher microleakage score than the non-exposed group.

\section{Materials and Methods}

Forty-five extracted intact human molars were obtained from the oral and maxillofacial surgery clinics and the Gavel Research Lab at Tufts University School of Dental Medicine (TUSDM). Extracted teeth were collected in a de-identified manner. Teeth were stored in an aqueous solution of $0.5 \%$ sodium hypochlorite (Bleach, Olinchloralkali, Cleveland, TN) at room temperature until the beginning of the study. For retention, a notch was created into the roots of all the teeth before they were vertically fixed in place with the cemento-enamel junction higher than the top of a mounting template by $1 \mathrm{~mm}$. To secure the teeth in place, orthodontic acrylic resin (Caulk Orthodontic Resin, DentsplyCaulk, Milford, DE) was used to fill the mounting templates. After teeth mounting, the occlusal surfaces of all the specimens were trimmed to a flat surface $4 \mathrm{~mm}$ above the surface of acrylic resin using a model trimmer (Whip Mix, Louisville, KY). Tooth preparation of a full-coverage crown was performed using a high-speed handpiece (Midwest Dentsply, Des Plaines, IL) that was connected to a surveyor (Degussa F1; DeguDent, Hanau, Germany) and water coolant system.

A diamond bur (847-16; Henry Schein, Melville, NY) was prepared at a six-degree angle from the vertical axis of the tooth to achieve a total convergence angle of 12 degrees. A custom jig (Lab-Putty, Coltene, Switzerland) was used to secure the mounted teeth vertically and to hold them immovably in the surveyor base. The axial surface was cut to $4.0 \mathrm{~mm}$ height and the depth of the axial surfaces was reduced by $1.5 \mathrm{~mm}$ to create a shoulder finish line. A fresh diamond bur (KD7W6 Brasseler, Savannah, GA) was used to smooth each sample. After the teeth preparations were completed, CEREC Optispray
(Dentsply Sirona, Long Island, NY) was sprayed on each prepared tooth before scanning. An optical impression was taken for each prepared tooth using the CAD/CAM machine (CEREC, Blue-cam, Bensheim, Germany). Each copping was designed to have a wall thickness of $2.0 \mathrm{~mm}$ in the contact area, $1.5 \mathrm{~mm}$ at the central fossa and 2.5 $\mathrm{mm}$ at the cusp tip with $100-\mu \mathrm{m}$ cement thickness (Figures $1 \& 2$ ). The crowns were milled from zirconiareinforced lithium silicate porcelain blocks (Celtra Duo, Dentsply international, Milford, DE) using the in-Lab MC XL milling unit (CEREC, Bensheim, Germany).
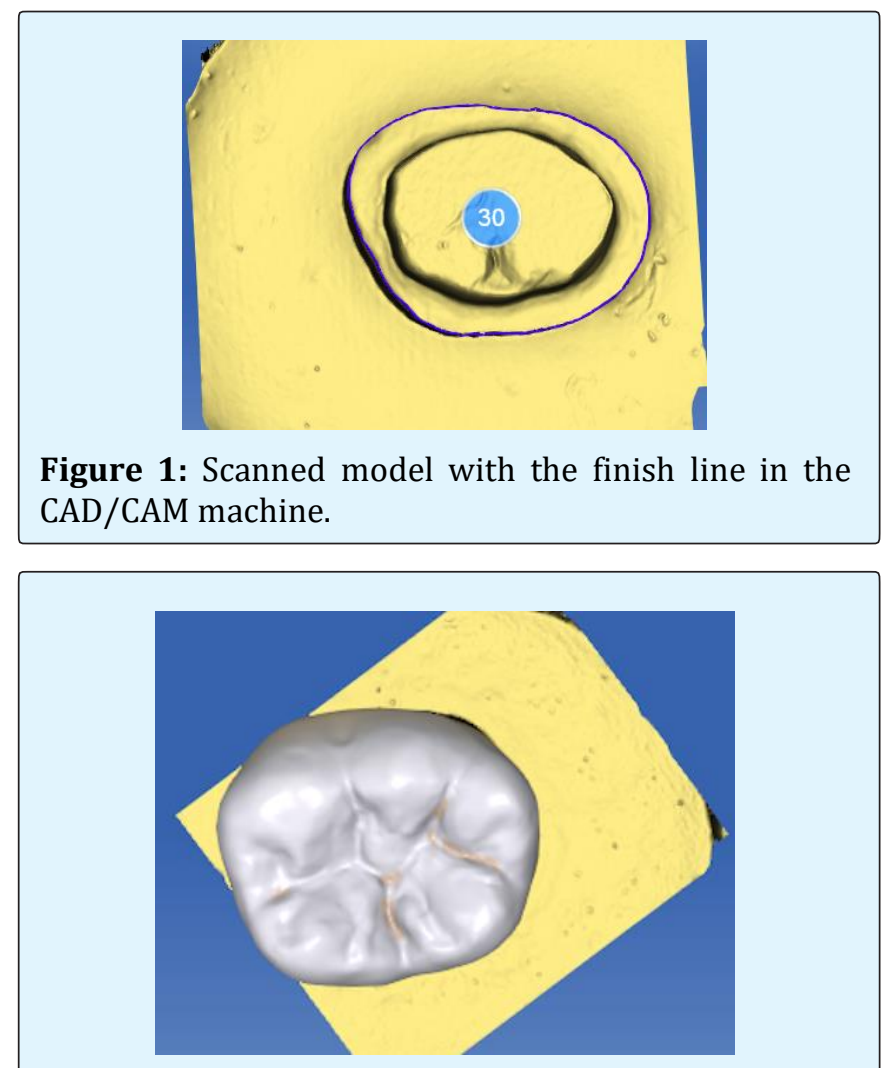

Figure 2: Design of crown in the CAD/CAM machine.

Prior to crown cementation, two trained calibrated prosthodontists evaluated the marginal adaptation using Modified United States Public Health Service criteria (USPHS/CDA) found in USPHS - Marginal Adaptation (Table 1) [39]. After milling was completed, every specimen was assigned a number using a Sharpie permanent marker. Specimens were divided randomly into three experimental groups ( $\mathrm{n}=10$ per group) and three control groups ( $\mathrm{n}=5$ per group) (Figure 3 ). 


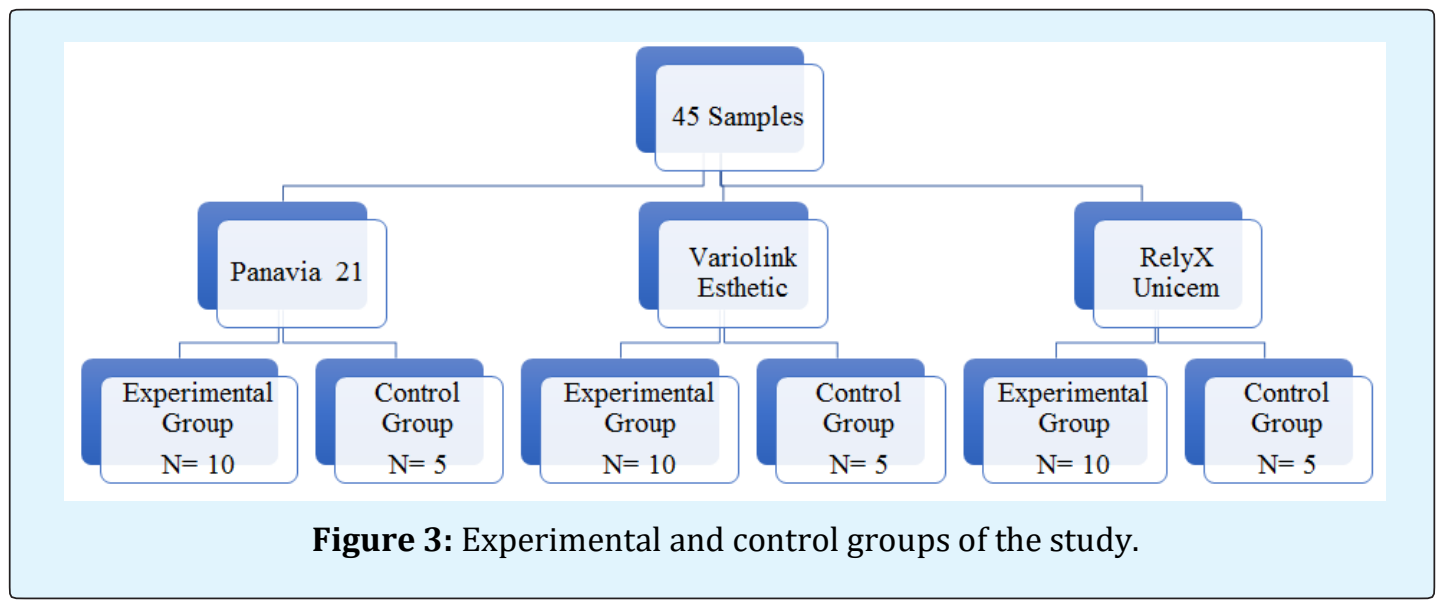

Crowns were cemented to their corresponding prepared teeth using three types of resin cement. The internal surface of each crown was acid etched with a 5\% solution of hydrofluoric acid (IvoclarVivadent, Schaan, Liechtenstein) for 20 seconds. A silane coupling agent (The Micro Dose, Premier, Plymouth Meeting, PA) was applied to the internal surface of each restoration for 60 seconds to increase the bond strength of cements then dried with a gentle air. The enamel surface of each prepared tooth was treated with a $37 \%$ solution of phosphoric acid for 15 seconds, rinsed with water and dried. Cement was dispensed from each tube, applied to the internal surface of the crowns and then crown was positioned on the respective tooth with finger pressure. Specimens were set in a loading machine (Instron, Model 5566; Canton, Mass) with a seating power of $50 \mathrm{~N}$ for five minutes in order to set under room temperature. Every specimen was light cured for 20 seconds on each surface. Excess cement was removed from all margins using a dental explorer No.23. Cemented copings were stored in tap water at $37^{\circ} \mathrm{C}$ for $24 \mathrm{~h}$, then thermocycled (Model: 1156, VWR, Germany) between water temperatures of $5^{\circ} \mathrm{C}$ and $55^{\circ} \mathrm{C}$ for 5,000 cycles with a 15 second dwell time at each temperature. Exposed surfaces of the teeth were coated with a layer of nail varnish to seal the open dentinal tubules. Samples in the experimental group were subjected to 91 cycles in hydrochloric acid 5\% (Dr. Clark digestive power, Chula Vista, CA) at $\mathrm{pH} 2$ for one hour, and then in artificial saliva $(\mathrm{pH}=6.7)$ for another one hour. The amount of time has been calculated according to the assumption that 91 hours equates to one year intraorally [40]. Control samples were immersed in artificial saliva for 91 hours. All the samples were embedded in clear epoxy resin (EpoKwick Resin, Buehler, Lake Bluff, IL), then sectioned in a buccolingual direction utilizing a 0.5 mm thickness and an eight-inch diameter diamond wheel (Isomet 1000, Buehler Ltd, Evanston, IL) (Figure 4). Both sections were analyzed, and all margins were evaluated under a stereomicroscope (SZX16, Olympus, Pennsylvania) at a magnification of $10 \mathrm{X}$. The specimens were scored by the percentage of color infiltration along the dentinal walls. The proportion of microleakage was calculated by dividing the total length of the dye penetration by the total length of the restoration (Figures 5 \& 6).

\begin{tabular}{|c|c|}
\hline R - Excellent / Ideal & $\begin{array}{c}\text { Explorer does not catch; continuous } \\
\text { adaptation and indistinguishable } \\
\text { margins. }\end{array}$ \\
\hline S - Acceptable & $\begin{array}{c}\text { Explorer detects but cannot } \\
\text { penetrate marginal area. }\end{array}$ \\
\hline $\begin{array}{c}\mathrm{T} \text { - Acceptable w/ } \\
\text { modifications }\end{array}$ & $\begin{array}{c}\text { Explorer detectable and penetrates } \\
\text { marginal area. }\end{array}$ \\
\hline $\mathrm{V}$ - Unacceptable & $\begin{array}{c}\text { Explorer detectable, gross marginal } \\
\text { discrepancies upon explorer } \\
\text { examination. }\end{array}$ \\
\hline
\end{tabular}

Table 1: Modified United States Public Health Service criteria (USPHS/CDA) USPHS-Marginal Adaptation.

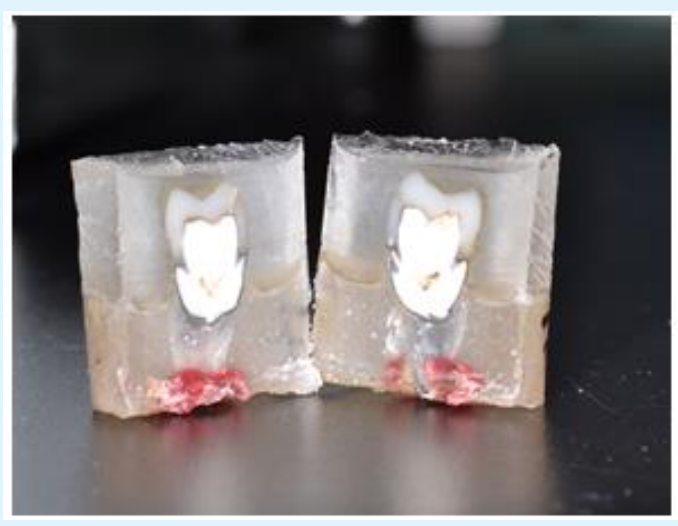

Figure 4: Sectioned sample. 


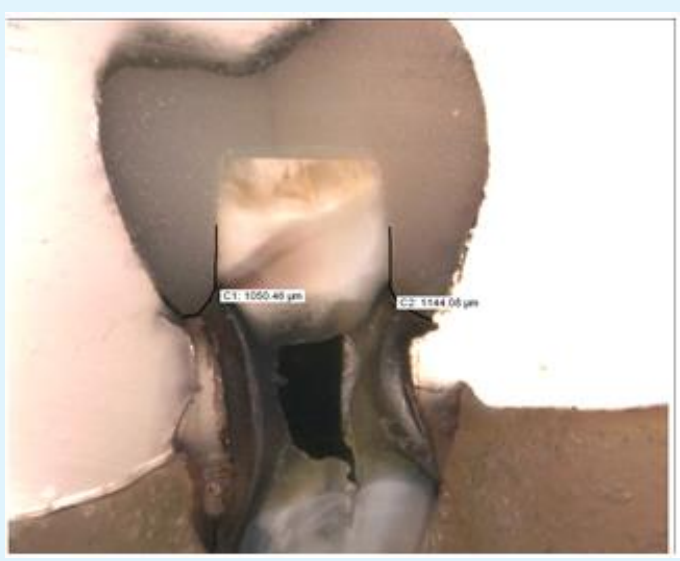

Figure 5: Extent of dye penetration in a sectioned tooth under stereomicroscope.

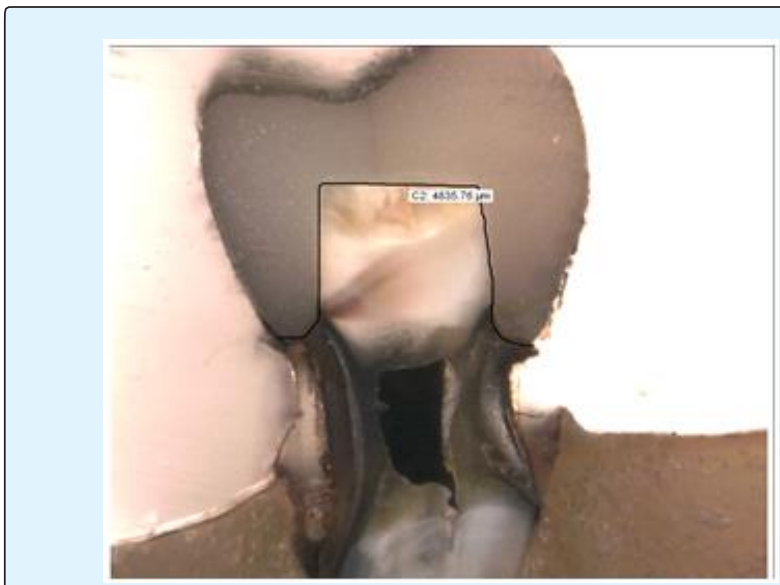

Figure 6: Total length of restoration in a sectioned tooth under stereomicroscope.

\section{Statistical Analysis}

Kruskal-Wallis test was performed to compare the microleakage score between groups. A Mann-Whitney U test and Bonferroni correction were used for post-hoc tests. Normality was assessed graphically and with a Kolmogorov-Smirnov test. The software SPSS version 24 was used for the statistical analysis. The software nQuery version 7.0 was used for the power calculation with a type I error rate of $5 \%$ and an effect size of 1.86 . A sample size of $n=10$ per experimental cement and $n=5$ per control cement was found to have $98 \%$ power to detect a difference in microleakage among the different resin cements. Descriptive statistics were calculated. Difference in median percentage microleakage was compared with Kruskal-Wallis test and the Mann-Whitney U test with the
Bonferroni correction for post-hoc comparisons. P-values less than 0.05 were considered statistically significant except in situations where the Bonteffori correction was applied. The software SPSS version 24 (IBM Corp, Armonk, NY) was used in the analysis.

\section{Results}

The study sample was divided into two groups; the experimental group included 30 molars ( $n=10$ per cement group), and the control group which is composed of 15 molars ( $n=5$ per cement group). After the procedure of teeth sectioning, two halves were obtained from each of the 45 specimens and an average of both sides was taken. Pairwise comparisons revealed statistically significant differences between Variolink esthetic in control group and experiment group ( $\mathrm{p}=.008)$, RelyX Unicem in control and experimental group ( $\mathrm{p}=.001)$ as well as Panavia 21 in control and experimental group $(\mathrm{p}=.001)$. Among the experimental groups: Panavia 21 showed the highest median microleakage score of $59.24 \% \quad(\mathrm{IQR}=25.88$ ), followed by RelyX UniCem and then Variolink Esthetic which had microleakage scores of $54.95 \%(\mathrm{IQR}=8.48)$ and $45.83 \%$ (IQR=36.11) respectively. Among the control groups: the median microleakage score for Variolink Esthetic was the highest among the control group at $32.82 \%$ (IQR=18.41). The median microleakage score for RelyX UniCem was the lowest at $21.81 \%$ (IQR=15.82) and the microleakage score for Panavia 21 was $25.49 \%$ (IQR= 10.50). Median microleakage scores and interquartile ranges are presented in Table 2 and boxplot of microleakage scores in all the groups in Figure 7.

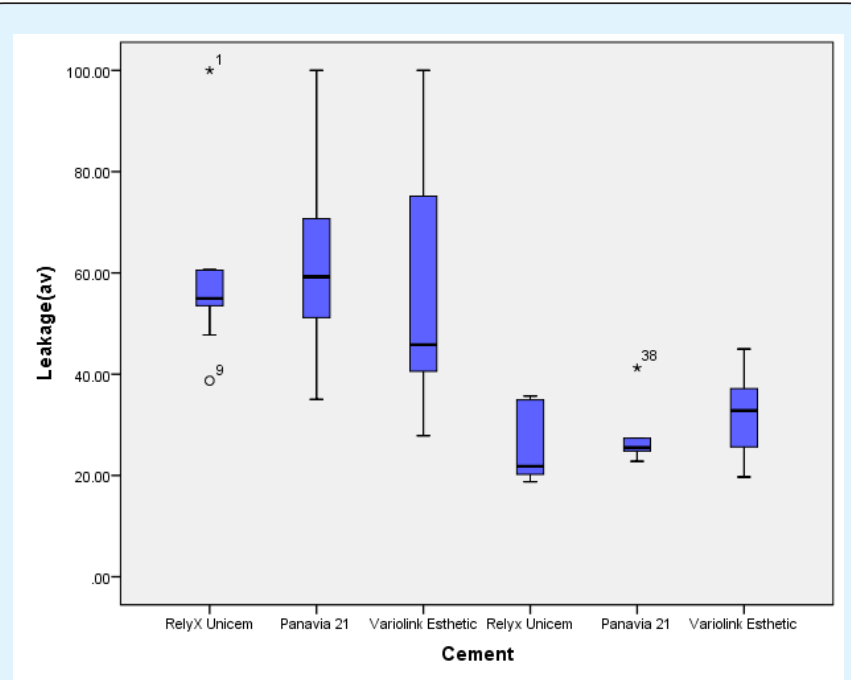

Figure 7: Boxplot of microleakage scores in all the groups. 


\section{Open Access Journal of Dental Sciences}

\begin{tabular}{|c|c|c|c|}
\hline & Resin Cement & Median & IQR \\
\hline \multirow{3}{*}{$\begin{array}{c}\text { Experimental } \\
\text { Groups }\end{array}$} & RelyX Unicem & $54.95^{\mathrm{A}}$ & 8.48 \\
\cline { 2 - 4 } & Panavia 21 & $59.24^{\mathrm{A}}$ & 25.88 \\
\cline { 2 - 4 } & Variolink Esthetic & $45.83^{\mathrm{AB}}$ & 36.11 \\
\hline \multirow{3}{*}{ Control Groups } & RelyX Unicem & $21.81^{\mathrm{C}}$ & 15.82 \\
\cline { 2 - 4 } & Panavia 21 & $25.49^{\mathrm{C}}$ & 10.5 \\
\cline { 2 - 4 } & Variolink Esthetic & $32.82^{\mathrm{BC}}$ & 18.41 \\
\hline
\end{tabular}

Table 2: Median microleakage scores and interquartile ranges of all cement groups.

\section{Discussion}

Resin cements are widely used due to their enhanced physical properties and their promising marginal seal [41]. It is well-known that the type of cement that was used for bonding, in this study has a strong impact on the microleakage value $[42,43]$. The objective of the current study was to evaluate the effect of hydrochloric acid on the microleakage of three different resin cements; RelyX UniCem, Panavia 21 and Variolink Esthetic after the immersion of zirconia-reinforced lithium silicate (ZLS) crowns (Celtra Duo) in hydrochloric acid solution.

The current study is the first to evaluate the effect of $\mathrm{HCl}$ on microleakage of resin cements used in cementation of all ceramic crowns, specifically ZLS. Evidence on this matter is very important to the dentist in order to select the most appropriate resin cement for those patients with GERD. Since the present study was performed in-vitro, it was not possible to demonstrate accurately the actual situation of the in-vivo effect of acid exposure. However, the most applicable method was used to simulate the oral cavity $\mathrm{pH}$ buffering process in patients' mouth by subjecting the samples to 91 one-hour cycles in $\mathrm{HCl}(\mathrm{pH} 2)$ followed by one hour in artificial saliva which represents one year of clinical exposure. This time interval was calculated and reported by Harryparsad, et al. and was formulated according to the theory that the GERD patient has an average of three purges per day, each of them lasting approximately five minutes $[40,44,45]$.

The results of the present study revealed that all experimental groups demonstrated higher microleakage scores than the control groups for all types of cement. Therefore, the hydrochloric acid solution increased the microleakage value in all types of cement used. There was no statistically significant difference among the experimental groups. However, Panavia 21 revealed the highest median microleakage value among all the groups with $59.24 \%$ while Variolink Esthetic showed the lowest with $45.83 \%$.
Similar results were reported in a study conducted by Cal, et al. who compared RelyX Unicem, Variolink II and some other resin cements in class $\mathrm{V}$ restorations. That study reported no statistically significant difference between Variolink II and RelyX Unicem cements at the gingival margin, which is in concordance with the current study. However, Variolink II showed the lowest microleakage value among the groups at the occlusal margin. That study did not evaluate the effect of $\mathrm{HCl}$ solution [46].

Similarly, with the experimental groups, in our study, there were no statistically significant differences among the resin cements in the control groups. However, Panavia 21 and RelyX Unicem showed the lowest microleakage scores in the control groups with $25.49 \%$ and $21.81 \%$ respectively. Under a stereomicroscope most of the samples in the experimental groups revealed extensive dye penetration, which was extended to the axial walls of both sides of the tooth. Conversely, samples of the control groups displayed lighter dye penetration only around the margins, which agreed with the results.

Although, Uludag, et al. exhibited a significant difference between Variolink II and Panavia 21, they also found that Panavia 21 had a higher microleakage value than Variolink II for both dentin and enamel margins [47]. This result was not in concordance with the study presented by Naumova, et al. which reported that the Panavia F 2.0 demonstrated the lowest microleakage score in comparison with RelyX Unicem and other types of resin cements [48]. Panavia F 2.0 and Panavia 21 are resin cements with the same composition; they only differ in the mode of curing and the fluoride release.

In the present study, RelyX Unicem revealed the lowest microleakage score in the control group. However, interestingly Variolink Esthetic exhibited the lowest microleakage score in the experimental group. This observation has some similarity with another in-vitro study conducted by Piwowarczyk, et al. who examined the microleakage of RelyX Unicem and Panavia F after four weeks of storing the specimen in distilled water. That study revealed a significant difference between the cements, and Panavia F presented a higher microleakage score than RelyX Unicem, a result that is in concordance with this current study [49]. Literature supports the fact that CAD/CAM restorations have a larger marginal gap than crowns fabricated by the conventional method $[50,51]$. This gap might have contributed to the amount of microleakage we found in the present study. Thus, resin 


\section{Open Access Journal of Dental Sciences}

cement would have a greater influence in reducing the amount of microleakage in CAD/CAM restorations.

There are some differences between the results of the present study and previously published studies. These differences might be attributed to the different ceramic materials, cementing agents and test conditions. The present study has some potential limitations. First, different results might be obtained in a clinical setting. As this is an in-vitro study, it may not simulate the real conditions in the oral cavity of GERD patients. Second, the current study was limited to commonly used resin cements, as well as to a single type of restoration, zirconia-reinforced lithium silicate crowns (ZLS). Further research may focus on investigating other types of ceramic materials, including different cements. Future prospective in-vivo studies and long follow-up times are also suggested in order to simulate the actual oral conditions in patients with GERD. The first null hypothesis was rejected as no statistically significant difference was found among the three experimental groups tested. The results of this study supported the second null hypothesis, according to which all the experimental groups exposed to the $\mathrm{HCl}$ exhibited a higher microleakage value than the non-exposed groups.

\section{Conclusion}

Within the limitations of this in-vitro study, the results indicate that none of the resin cements investigated in the study produced microleakage-free restorations. Microleakage value increased when specimens were exposed to the $\mathrm{HCl}$ solution. Therefore, acid exposure increases resin-based cement degradation. Dentists may consider that when treating patients with gastroesophageal reflux since the longevity of the restorations might be affected if the symptoms persist. Restorations for those patients may require long-term maintenance.

\section{Acknowledgement}

The study was presented in a poster presentation at the 47th IADR General Session and Exhibition, Fort Lauderdale, Fla March 21-24, 2018. The authors reported no conflicts of interest related to this study.

\section{References}

1. Haselton DR, Diaz-Arnold AM, Hillis SL (2000) Clinical assessment of high-strength all-ceramic crowns. J Prosthet Dent 83(4): 396-401.

Tsakalelli V, et al. Effect of Hydrochloric Acid on Resin Cement Microleakage in Zirconia-Reinforced Lithium Silicate Crowns. J Dental Sci 2019, 4(4): 000239.
2. Pjetursson BE, Sailer I, Zwahlen M, Hammerle CHF (2007) A systematic review of the survival and complication rates of all-ceramic and metal-ceramic reconstructions after an observation period of at least 3 years. Part I: Single crowns. Clin Oral Implants Res 18(3): 73-85.

3. Sailer I, Pjetursson BE, Zwahlen M, Hammerle CHF (2007) A systematic review of the survival and complication rates of all-ceramic and metal-ceramic reconstructions after an observation period of at least 3 years. Part II: Fixed dental prostheses. Clin Oral Implants Res 18(3): 86-96.

4. Kelly JR, Nishimura I, Campbell SD (1996) Ceramics in dentistry: historical roots and current perspectives. J Prosthet Dent 75(1): 18-32.

5. Mormann WH, Bindl A (2002) All-ceramic, chair-side computer-aided design/computer-aided machining restorations. Dent Clin North Am 46(2): 405-426.

6. Beuer F, Schweiger, Edelhoff D (2008) Digital dentistry: an overview of recent developments for CAD/CAM generated restorations. Br Dent J 204(9): 505-511.

7. Li RWK, Chow TW, Matinlinna JP (2014) Ceramic dental biomaterials and CAD/CAM technology: State of the art. J Prosthodont Res 58(4): 208-216.

8. Gu XH, Kern M (2003) Marginal discrepancies and leakage of all-ceramic crowns: influence of luting agents and aging conditions. Int J Prosthodont 16(2): 109-116.

9. El-Mowafy O (2001) The use of resin cements in restorative dentistry to overcome retention problems. J Can Dent Assoc 67(2): 97-102.

10. Li ZC, White SN (1999) Mechanical properties of dental luting cements. J Prosthet Dent 81(5): 597609.

11. Piwowarczyk A, Lauer HC (2003) Mechanical properties of luting cements after water storage. Oper Dent 28(5): 535-542.

12. Sakaguchi RL, Powers JM Craig's Restorative Dental Materials. $12^{\text {th }}$ (Edn.), Elsevier-Mosby Co., pp: 342344. 


\section{Open Access Journal of Dental Sciences}

13. Stamatacos C, Simon JF (2013) Cementation of indirect restorations: an overview of resin cements. Compend Contin Educ Dent 34(1): 42-44,46.

14. Santos GC, Santos MJ, Rizkalla AS (2009) Adhesive cementation of etchable ceramic esthetic restorations. J Can Dent Assoc 75(5): 379-384.

15. Kim BK, Bae HE, Shim JS, Lee KW (2005) The influence of ceramic surface treatments on the tensile bond strength of composite resin to all-ceramic coping materials. J Prosthet Dent 94(4): 357-362.

16. Kern M (2009) Resin Bonding to Oxide Ceramics for Dental Restorations. Journal of Adhesion Science and Technology 23(7-8): 1097-1111.

17. Kidd EA (1976) Microleakage: a review. J Dent 4(5): 199-206.

18. Goodacre CJ, Bernal G, Rungcharassaeng K, Kan JY (2003) Clinical complications in fixed prosthodontics. J Prosthet Dent 90(1): 31-41.

19. Bergenholtz G, Cox CF, Loeshe WJ, Syed SA (1982) Bacterial leakage around dental restorations: its effect on the dental pulp. J Oral Pathol 11(6): 439450 .

20. Goldman M, Laosonthorn P, White RR (1992) Microleakage--full crowns and the dental pulp. J Endod 18(10): 473-475.

21. Schmid-Schwapa M, Graf A, Preinerstorfer A, Watts D, Piehslinger E, et al. (2001) Microleakage after thermocycling of cemented crowns-A meta-analysis. Dent Mater 27(9): 855-869.

22. Nakamura T, Dei N, Kojima T, Wakabayashi K (2003) Marginal and Internal Fit of Cerec 3 CAD/CAM AllCeramic Crowns. Int J Prosthodont 16(3): 244-248.

23. Contrepois M, Soenen A, Bartala M, Laviole 0 (2013) Marginal adaptation of ceramic crowns: A systematic review. J Prosthet Dent 110(6): 447-454.

24. Vakil N, van Zanten SV, Kahrilas P, Dent J, Jones R (2006) The Montreal definition and classification of gastroesophageal reflux disease: a global evidencebased consensus. Am J Gastroenterol 101(8): 19001920.

25. Bartlett DW, Evans DF, Anggiansah A, Smith BGN (1996) A study of the association between gastro- oesophageal reflux and palatal dental erosion. Brit Dent J 181(4): 125-131.

26. Barron RP, Carmichael RP, Marcon MA, Sandor GK (2003) Dental erosion in gastroesophageal reflux disease. J Can Dent Assoc 69(2): 84-89.

27. Sujatha S, Jalihal U, Devi Y, Rakesh N, Chauhan P, et al. (2016) Oral pH in gastroesophageal reflux disease. Indian J Gastroenterol 35(3): 186-189.

28. Mihailopol CF, Topoliceanu C, Ghiorghe CA, Galina Pancu, Carmen M Codreanu (2011) Correlations between dental erosion severity and salivary factor in patients with gastroesophageal reflux disease. Romanian Journal of Oral Rehabilitation 3(4): 63-66.

29. Moazzez R, Bartlett D, Anggiansah A (2004) Dental erosion, gastro-oesophageal reflux disease and saliva: how are they related? J Dent 32(6): 489-494.

30. Campisi G, Lo Russo L, Di Liberto C, Di Nicola F, Butera D, et al. (2008) Saliva variations in gastrooesophageal reflux disease. J Dent 36(4): 268-271.

31. Larsen MJ (1990) Chemical events during tooth dissolution. J Dent Res 69: 575-580, 634-636.

32. Lazarchik DA, Filler SJ (1997) Effects of gastroesophageal reflux on the oral cavity. Am J Med 103(5): 107-113.

33. Pace F, Pallotta S, Tonini M, Vakil N, Porro B (2008) Systematic review: gastro-oesophageal reflux disease and dental lesions. Aliment Pharmacol Ther 27(12): 1179-1186.

34. Ranjitkar S, Smales RJ, Kaidonis JA (2012) Oral manifestations of gastroesophageal reflux disease. J Gastroenterol Hepatol 27(1): 21-27.

35. Van Roekel NB (2003) Gastroesophageal reflux disease, tooth erosion, and prosthodontic rehabilitation: a clinical report. J Prosthodont 12(4): 255-259.

36. Gandara BK, Truelove EL (1999) Diagnosis and management of dental erosion. J Contemp Dent Pract 1(1): 16-23.

37. Milleding P, Haraldsson C, Karlsson S (2002) Ion leaching from dental ceramics during static in vitro corrosion testing. J Biomed Mater Res 61(4): 541-550. 


\section{Open Access Journal of Dental Sciences}

38. Matsou E, Vouroutzis N, Kontonasaki E, Paraskevopoulos KM, Koidis P (2011) Investigation of the influence of gastric acid on the surface roughness of ceramic materials of metal-ceramic restorations. An in vitro study. Int J Prosthodont 24(1): 26-29.

39. Bayne SC, Schmalz G (2005) Reprinting the classic article on USPHS evaluation methods for measuring the clinical research performance of restorative materials. Clin Oral Investig 9(4): 209-214.

40. Harryparsad A, Dullabh H, Sykes L, Herbst D (2014) The effects of hydrochloric acid on all-ceramic restorative materials: an in-vitro study. SADJ 69(3): 106-111.

41. Jaberi Ansari Z, Kalantar Motamedi M (2014) Microleakage of two self-adhesive cements in the enamel and dentin after 24 hours and two months. J Dent 11(4): 418-427.

42. White SN, Sorensen JA, Kang SK, Caputo AA (1992) Microleakage of new crown and fixed partial denture luting agents. J Prosthet Dent 67(2): 156-161.

43. Shortall AC, Fayyad MA, Williams JD (1989) Marginal seal of injection-molded ceramic crowns cemented with three adhesive systems. J Prosthet Dent 61(1): 24-27.

44. Hetherington MM, Altemus M, Nelson ML, Bernat AS, Gold PW (1994) Eating behavior in bulimia nervosa: multiple meal analyses. Am J Clin Nutr 60(6): 864873.

45. McLaren EA, Cao PT (2009) Ceramics in dentistrypart 1: classes of materials. Inside Dentistry pp: 94104.

46. Cal E, Celik EU, Turkun M (2012) Microleakage of IPS empress 2 inlay restorations luted with self-adhesive resin cements. Oper Dent 37(4): 417-424.

47. Uludag B, Ozturk O, Ozturk AN (2009) Microleakage of ceramic inlays luted with different resin Cements and dentin adhesives. J Prosthet Dent 102(4): 235241.

48. Naumova EA, Valta A, Schaper K, Arnold WH, Piwowarczyk A (2015) Microleakage of Different SelfAdhesive Materials for Lithium Disilicate CAD/CAM Crowns. Materials 8(6): 3238-3253.

49. Piwowarczyk A, Lauer HC, Sorensen JA (2005) Microleakage of various cementing agents for full cast crowns. Dent Mater 21(5): 445-453.

50. Reich S, Uhlen S, Gozdowski S, Lohbauer U (2011) Measurement of cement thickness under lithium disilicate crowns using an impression material technique. Clin Oral Investig 15(4): 521-526.

51. Abo T, Uno S, Sano H (2004) Comparison of bonding efficacy of an all-in-one adhesive with a self-etching primer system. Eur J Oral Sci 112(3): 286-292. 